and other details of the protocol. The effect of this adjustment was to reduce our estimated increase in mean dose-response ratio between 1982 and 1992.

Until Booth and colleagues publish the details of their methods and their data, and until clinical data on the practical effects of differences between nebulisers are available, we suggest that our method of adjusting for methodologica differences on the basis of our own epidemiological data was the most accurate adjustment that could be made. Using that adjustment, we found that the level of airway responsiveness had increased between 1982 and 1992 in both study regions. This finding, which supported our conclusions that the children studied in 1992 had a higher prevalence of airway hyperresponsiveness than the children studied in 1982, is consistent with other Australian studies that have reported a significant increase in the prevalence and severity of asthma. ${ }^{34}$

JENNIFER K PEAT Senior research fellow CHERYL M SALOME Senior research office ANN J WOOLCOCK

Department of Medicine, Professor of respiratory medicine

University of Sydney,

NSW 2006,

Australia

1 Booth H, Hartley-Sharpe C, Walters H. Asthma trends. $B M f$ 1994;309:603. (3 September.)

2 Peat JK, van den Berg RH, Green W, Mellis CM, Leeder SR, children. BMF 1994;308:1591-6. (18 June.)

3 Robertson CF, Heycock E, Bishop J, Nolan T, Olinsky A

Phelan P. Prevalence of asthma in Melbourne schoolchildren: changes over 26 years. BMf 1991;302:1116-8.

4 Kun HY, Oates RK, Mellis CM. Hospital admissions and attendances for asthma - a true increase? Med $\mathcal{F}$ Aust 1993;159. 312-3.

\section{Smoking and death}

EDITOR,-It is interesting to contrast the survival curves for the British male doctors studied by Doll and colleagues' with what is, to my knowledge, the first published lifetable for smokers and nonsmokers. This was computed by Pearl in 1938 in an "investigation of the influence of tobacco upon human longevity" in American men. ${ }^{2}$ The figure shows survival in the British (fig (a) and (b)) and American (fig (c)) studies.

In the British study the population is homogeneous in occupation and social class and is large (34439 subjects); qualitative and quantitative information is available on smoking habits; and the population has been followed up for 40 years, longer than any other cohort. In the American study the population was heterogeneous in occupation and social class and was comparatively smal (6813 subjects); smoking habits were more broadly defined (non-users of tobacco, 2094; moderate smokers, 2814; heavy smokers, 1905); and the population was observed over a restricted period. Still there is a close resemblance between the differences in survival between smokers and nonsmokers in the two populations, particularly when Woolcock AJ. Changing prevalence of asthma in Australian

the earlier period (1951-71 (figure $(a)$ ) is considered for the British doctors.

Although the average (median) age of survival for subjects older than 35 is nearly 79 for the British doctors and only 69 for the American men, reflecting the differences between the two populations, the studies, and the epochs of observation, the loss of survival for smokers compared with non-smokers (averaging over moderate and heavy smokers in the American data) is five years for the British doctors (figure (a)) and 4.9 years for the American men.

There may be an element of chance in such nearly exact concordance, but it is unlikely to be a major one: Pearl stated that "the smoking of tobacco was statistically associated with an impairment of life duration, and the amount or degree of this impairment increased as the habitual amount of smoking increased." We know today that such an impairment-which has increased in recent times with increasing survival of non-smokers (figure $(b)$ )-arises from the specific diseases and deaths caused by smoking. Coincidentally, Pearl's remark is the type of remark that Richard Peto makes in his letter on the nature of the evidence available on the issue of smoking and health in the late 1930 s. $^{3}$

RODOLFO SARACCI Director of research in epidemiology International Agency for Research on Cancer, 69372 Lyons Cedex 08,

France

1 Doll R, Peto R, Wheatley K, Gray R, Sutherland I. Mortality in relation to smoking; 40 years' observations on male British doctors. BMF 1994:309:901-11. (8 October)

Pearl R. Tobacco smoking and longevity. Science 1938;87:216-7.

3 Peto R. Smoking and death. BMF 1995;310:396. (11 February.)

\section{Care of dying patients in hospital}

EDITOR,-Nicholas Albery is shocked by the way in which Mina Mills appeared to neglect the needs of dying patients while she was a non-participant observer researching the care of patients dying in hospital and regrets the delay in publishing the research. ${ }^{1}$ Mills and colleagues explain that the delay occurred partly because of antipathy to the findings. ${ }^{2}$ This turning of a blind eye, albeit to the unbearable, underlines the need for the research.

There was a similar reluctance 50 years ago when Bowlby, Spence, Winnicott, MacCarthy, and a few others tried to develop the rational and humane care of children in hospital; the need for unrestricted visiting and, especially, for mothers or fathers to say in hospital with their young children was recognised. In despair, in 1953 James Robertson made his film $A$ Two Year Old Goes to Hospital-a film using non-participant observation. Because the film was so upsetting Robertson experienced similar antipathy to that experienced by Mills and colleagues. Some doctors suggested that the film was of a specially selected disturbed child, and one thought that the film was a fake. This film was, and remains, influential.
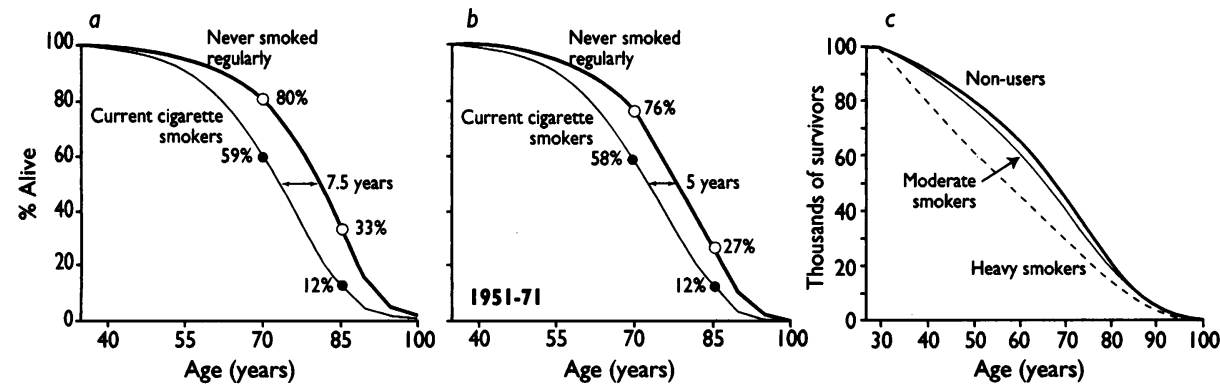

Survival of (a) British doctors 1951-71 and (b) British doctors 1951-91 from Doll and colleagues' study and (c) of American men in 1930s. Figure (c) is adapted from Pearl" with permission of "Science" (copyright 1995 American Association for the Advancement of Science)
Had these doctors been able to allow themselves to notice the misery of the young children in their own wards - to be participant observers-Robertson need not have made the film.

Participant and non-participant observation of miserable and neglected patients is hard and requires training. Mills should be congratulated. People need help to cope with the complex feelings of helplessness, despair, shame, and guilt stirred up by caring for those who are sick. ${ }^{3}$ The help needs to be continuing and is probably best provided in small group discussions led by experienced trained staff. Maybe another film with nonparticipant observation needs to be made.

EMANUEL LEWTS

\section{Adult Department,}

Consultant psychotherapist

Tavistock Clinic,

London NW3 5BA

1 Albery N. Care of dying patients in hospital. BMF 1994;309: 1579. (10 December.)

2 Davies HTO, Macrae WA, Mills M. Care of dying patients in hospital. BMF 1994;309:1579. (10 December.)

3 Bourne S, Lewis E. Doctors despair: a paradox of progress. $f R$ Coll Gen Pract 1977;27:37-9.

\section{New or old antidepressants?}

EDITOR,-In their article on the new antidepressants Harrison and Owens mention that "certain depressed patients may require a broader spectrum of synaptic blockade than that offered by the selective serotonin reuptake inhibitors." Surely the idea is to enhance transmission at serotoninergic synapses by presynaptic reuptake blockade, which is rather different from synaptic blockade.

W A HENDERSON

St Nicholas Hospital,

Registrar in psychiotio

Gosforth,

Newcastle upon Tyne NE3 3XT

1 Harrison G, Owens D. New or old antidepressants? $B M$ 1994;309:1280-2. (12 November.)

\section{Author's reply}

EDrTor,-It is now clear that there is not a single 5-hydroxytryptamine or noradrenaline receptor but a family of receptors subserving different functions at presynaptic and postsynaptic sites. Different antidepressants seem to have both sensitising and desensitising effects on postsynaptic 5-hydroxytryptamine receptors, and evidence exists of adaptive reduction in receptor binding sites after long term administration.

Because of the evidence of agonistic and antagonistic effects associated with different antidepressants, at both the presynaptic and postsynaptic levels, the term receptor regulation would have been more comprehensive than blockade. The point is that we shall continue to need a range of old and new antidepressants to meet the needs of our patients.

GLYNN HARRISON Professor of community mental health

Department of Psychiatry,

Faculty of Medicine,

Professorial Unit, Mapperley Hospital,

Nottingham NG3 6AA

\section{Breast disease}

EDIToR,-Justine Foster advocates aspiration of breast cysts by general practitioners in their surgery because, in her experience, "the first thing a surgeon would do is attempt to aspirate the cyst." While we accept that it is appropriate for general practitioners to aspirate cysts of patients known to have recurrent cystic disease, we do not believe that this is appropriate for patients who 
have no history of cysts; these patients should be referred to hospital. Mammography is the first investigation that should be performed in a woman in the age range affected by cysts because it provides useful diagnostic information in patients with a breast mass; roughly $1 \%$ of patients with a cyst have a breast cancer at the time that they present with the cyst, and this can be identified on mammography; prior needle aspiration increases the pain and discomfort associated with mammography; and fine needle aspiration performed before mammography may cause a haematoma, which mammographically may mimic a breast cancer. ${ }^{2}$

Results of mammography in series of 500 symptomatic patients

\begin{tabular}{lcc}
\hline & \multicolumn{2}{c}{ Final pathological diagnosis } \\
\cline { 2 - 3 } Mammographic & Malignant & Benign \\
\hline diagnosis & 75 & 4 \\
Malignant & 11 & 36 \\
Suspicious & 14 & 360 \\
Benign or normal & &
\end{tabular}

Sensitivity (includes malignant and suspicious diagnoses) $=$ $(75+11) / 100=86 \%$

Specificity $=360 / 400=90 \%$.

Positive predictive value of a malignant diagnosis $=75 /(75+$ 4) $=95 \%$.
Positive

James W T Chalmers and David Breen make several errors in their back calculation of the sensitivity, specificity, and positive predictive value of tests used to diagnose breast cancer. ${ }^{3}$ The table presents results of mammography in a series of 500 patients; the results are classified as malignant, suggestive of malignancy, or benign or normal. The figures show how, with a prevalence of breast cancer in this group of $20 \%$, it is possible to obtain a sensitivity of $86 \%$, a specificity of $90 \%$, and a positive predictive value of a malignant diagnosis of $95 \%$. Chalmers and Breen calculate that, to obtain these results (which are the same as those set out in our article $)$, there had to be a prevalence of malignant disease of $69 \%$. Their calculations are incorrect. In our view the results given for the accuracy of investigations of symptomatic breast disease ${ }^{+}$should be attainable in units seeing appreciable numbers of patients with breast problems.

J MICHAEL DIXON

Department of Surgery

University of Edinburgh,

Royal Infirmary,

Edinburgh EH3 $9 \mathrm{YW}$

RE MANSEL.

University of Wales College of Medicine,

Professor of surgery

Cardiff CF 4 XN

1 Foster J. Referral of women with breast lumps. $B M \mathcal{F} 1995 ; 310$ : 331. (4 February.)

2 Sickles EA, Klein DL, Goodson WH, Hunt TK. Mammography after fine needle aspiration of palpable breast masses. $A m g$ Surg 1983;145:392-7.

3 Chalmers JWT, Breen D. Positive predictive value of tests for breast disease. $B M 7$ 1995;310:331. (4 February.)

4 Dixon JM, Mansel RE. ABC of breast diseases: symptoms, assessment and guidelines for referral. $B M \mathcal{F}$ 1994;309:722-6. (17 September.)

\section{Medical informatics}

EDITOR,-We agree with Anthony Nowlan that "technological advance alone is not sufficient because much of the hard part is bound up with the way in which we practise medicine, and this cannot be addressed only by the medical profession." The conference "The heart of the matter," organised jointly by the British Medical Informatics Society and the BMA last December, showed that there is a lot of interest in medical informatics, but discussion there emphasised the need to address the lack of education for both students and clinicians.
Other countries have taken a lead in tackling this at the national level by making substantial changes to medical education. For example, medica informatics has been included in the nationally regulated medical curriculum in Germany since $1980 .^{2}$ In the mid-1980s the Association of American Medical Colleges recommended that "medical schools should designate an academic unit for institutional leadership in the application of information science and computer technology to the general professional education of physicians and promote their effective use."

The changes to the undergraduate medical curriculum that are currently being planned in most medical schools in Britain offer an idea opportunity to review the place of medical informatics in the curriculum and in universities. We believe that medical informatics should be integrated as a core part of a problem based approach to medical education and that each university with a medical undergraduate course needs a group, unit, or department of medical informatics in recognition of the future role of the discipline. This unit would not necessarily be located solely in the medical faculty but might also have roots in computing or information science.

RAY JONES Senior lecturer in health informatics SUE KINN

Research fellow, postgraduate medical educatio FELICITY GRAINGE

University of Glasgow,

Glasgow G12 8R7.

Nowlan A. Medical informatics: the professional challenge. $B M F$ 1994;309:1385-6. (26 November.)

Haux R, Dudeck J, Gaus W, Leven FJ, Kunath H, Michaelis J, et al. Recommendations of the German Association for Medical Informatics, Biometry and Epidemiology for education an training in medical informatics. Methods Inf Med 1992;31 60-70.

3 Executive Council of the Association of American Medical Colleges. Evaluation of medical information science in medical education. F Med Educ 1986;61:487-543.

\section{Memory of intraoperative events}

EDIToR,-We were disappointed to read in J G Jones's editorial on memory of intraoperative events that Jones believes that the isolated forearm technique is "unsuitable for prolonged monitoring because of the risk of ischaemia in the isolated arm." We have described how prolonged monitoring is easily achieved simply by releasing the forearm cuff after 20 minutes and then reinflating it some minutes later if further muscle relaxation is required..$^{23}$ This cycle of isolation of the forearm and release can then be maintained indefinitely. Using "train of four" nerve stimulation in more than 100 cases, we have found that although releasing the tourniquet after 20 minutes results in some reduction in muscle power, this is not sufficient seriously to impair the capacity for forearm responses. This technique assumes the use of a non-depolarising muscle relaxant such as atracurium or vecuronium in appropriate doses (the technique is not viable with pancuronium).

We are puzzled by the anaesthetic community's continued resistance to the more widespread use of the isolated forearm technique, despite Jones's description of the method as the gold standard against which other methods of detecting awareness need to be evaluated. ${ }^{4}$ This may have something to do with contemporary anaesthetic culture, in which simple clinical methods are overlooked in favour of high tech monitoring techniques. Even if a reliable monitoring device became commercially available in the near future (and this is unlikely) the cost of equipping every operating theatre in Britain with such a machine would be exorbitant. For example, at $£ 5000$ per machine (a conservative estimate) the total cost to the NHS would be in the region of $£ 20 \mathrm{~m}$-an unrealistic prospect in today's cost cutting, accountancy led service. This potential expense is in stark contrast to that of the isolated forearm technique, which uses equipment readily available in every operating theatre. With a relatively low but persistent incidence of awareness with postoperative recall, often associated with the threat of litigation, can anaesthetists afford to remain complacent about these matters?

Jones also states that "the psychological consequences of conscious awareness with explicit memory of pain are not known." Although a definitive follow up study of a sizeable cohort has yet to be published, there are numerous reports of small groups and single cases. When appreciable psychological distress is evident it inevitably falls within the parameters of post-traumatic stress disorder, being characterised by symptoms of excessive autonomic arousal (including panic, anxiety, and fear), intrusive re-experiencing of the original trauma (for example, flashbacks and nightmares), and avoidance (for example, the development of phobic disorder and attempts to avoid reminders of the trauma). These disturbances commonly last for years rather than months. What certainly is unknown is the psychological effect of intraoperative awareness and pain without explicit postoperative recall. Many people assume that this has no consequence, but this has yet to be proved. There are anecdotal suggestions that such experiences may have serious and enduring psychological sequelae. ${ }^{5}$

MICHAEL WANG

Clinical Psychology Unit,

Clinical director

University of Hull,

Hull HU6 7RX

Department of Anaesthesia,

IAN F RUSSELL

Hull HU3 2JZ

1 Jones JG. Memory of intraoperative events. BMF 1994;309: 967-8. (15 October.)

2 Russell IF. Conscious awareness during general anaesthesia. In Jones JG, ed. Depth of anaesthesia: Balliere's clinical anaesthesiology. London: Ballière-Tindall, 1989:511-32.

3 Wang M, Russell IF, Charlton FC, Conlon J. An experimental simulation of anaesthetic awareness and validation of the isolated forearm technique. In: Sebel P, Bonke B, Winograd E, eds. Memory and awareness in anaesthesia. Englewood Cliffs, NJ: Prentice-Hall, 1993:434-46.

4 Jessop J, Jones JG. Conscious awareness during general anaesthesia-what are we attempting to monitor? $\mathrm{Br} f$ Anaes 1991;66:635-7.

5 Tunstall M, Lowit IM. Sleep phobia after awareness during general anaesthesia. BMF 1982;285:865.

\section{Preventing suicide}

EDIToR,-Andrew Warsop is to be congratulated for having the courage to put his head above the parapets in the challenging debate about the rights of individuals and the duty of doctors with regard to suicide. ${ }^{1}$ This debate, however, does not belong to the medical profession alone. For over 40 years the Samaritans has offered emotional support to those for whom life may have become too much to bear. The question about the rights of individuals to self determination continues to be a constant source of debate. One of the fundamental principles that governs the way in which the Samaritans works states, "A caller does not lose the freedom to make his own decisions, including the decision to take his own life, and is free to break contact at any time."

Principles, however, are one thing (as guidelines, codes of ethics, etc may be), but practice presents the stark reality of decisions that need to be made and assumptions that have to be taken. For example, who can possibly tell (within the time available for a decision to be made) that a person who is unconscious, having apparently taken an overdose, really does want to die? Death is irreversible, whereas someone who is resuscitated will 